\title{
Commercialization Suitability Evaluation of Historical and Cultural Blocks in Beijing, China
}

\author{
Jiayao Zhao, Sarana Photchanachan \\ School of Management, Shinawatra University, Bangkok, Thailand \\ Email: zhaojiayao@lfnu.edu.cn, sarana.p@siu.ac.th
}

How to cite this paper: Zhao, J. Y., \& Photchanachan, S. (2021). Commercialization Suitability Evaluation of Historical and Cultural Blocks in Beijing, China. Journal of Service Science and Management, 14, 343-352.

https://doi.org/10.4236/jssm.2021.143021

Received: May 10, 2021

Accepted: June 18, 2021

Published: June 21, 2021

Copyright $\odot 2021$ by author(s) and Scientific Research Publishing Inc. This work is licensed under the Creative Commons Attribution International License (CC BY 4.0).

http://creativecommons.org/licenses/by/4.0/

\begin{abstract}
Based on the evaluation cognition and taking the commercialization degree of the historical blocks as the object, this paper makes an in-depth discussion on the protection and commercial development and utilization of the historical block, in order to enrich the research field of the protection of the historical and cultural block and provide reference suggestions for the protection practice of the block. Relevant literature and practical experience of protection and development in terms of protection evaluation, commercialization and suitability research at home and abroad are sorted out and summarized, which lays a theoretical and practical foundation for the development of this paper. From three aspects of the inevitability of the commercial development of historical and cultural blocks, the various contradictions caused by improper commercialization and the urgent appeal for the proper commercialization of blocks from the social, economic, cultural and life levels, the necessity of conducting commercial suitability research is put forward.
\end{abstract}

\section{Keywords}

Historical and Cultural Blocks, Commercialization Suitability Evaluation, Polices

\section{Introduction}

In the past several decades, many researchers have undertaken the studies on the subject of management of activation conservation of historic buildings. Liao (2017) showed in the process of protection and development, because different stakeholders have different goals and complex relationships, some sharp contradictions and standards of commercialization suitability evaluation arise. Demolition of original residents in the early stage of development of historical and cultural blocks; Business disputes between development subjects; The contradic- 
tion between excessive commercialization and sustainable economic development; The lack of funds to protect the historical and cultural blocks affects the scientific nature of protection; The long-term benefit problem in the development of commercial management. These problems are affecting the sustainable development of historical and cultural blocks conservation. Ge (2007) pointed the speed of the commercialization process has different effects on the historical districts, which mainly shows three states: under-commercialization, moderate commercialization and over-commercialization. The lack of commercialization has led to the dilapidation of historic districts and the destruction of cultural heritage. Excessive commercialization diluted the cultural atmosphere of the historic district, and the cultural space was damaged to varying degrees. In the historical block commercial phenomenon intensified today, how to realize the moderate commercial development, reserved for blocks into the economic development, social development and cultural value, historical block effective protection, the residents to live and work in peace and contentment, maintain good living environment, historical block as native blocks, related management department, planning and technical personnel, and the focus of the people from all walks of life.

\section{Literature Review}

Lan (2015) proposed that activated conservation was not excessive commercialization, but the so-called excessive commercial "kill" of ancient buildings. Just as cultural heritage is called "cultural wealth" in Japan, the Japanese treats cultural heritage as a wealth. de Santoli (2009) found that a series of management strategies, such as developing tourism, building theme parks and building creative industries were put forward for the concept of historical buildings conservation and management. Wu (2012) meanwhile found that "Activation" was to re-endue historic buildings with cultural significance or use scenes to re-integrate it into modern life, so as to solve the contradiction of "heritage protection restricts development and development destroys heritage protection." Ruan (2015) later found that with culture as the leading factor, culture and life were revitalized, protected and restored. Every cities is similar, exhausted the original intention of historical building protection.

Meanwhile, the historical and cultural city has undergone protection and exploration for more than ten years. Through commercial stimulation and tourism promotion, the commercialization phenomenon has had a great impact on the protection and development of historical and cultural cities. Excessive commercial development has gradually transformed the historical and cultural district into a modern commercial street and a shopping pedestrian street. It is impossible to feel the historical and cultural heritage of the neighborhood. The architectural style, the blockscape and the sculpture completely become the empty shell of culture. Xing (2019) found that the discovery of residential historical blocks is characterized by the integration of "lifestyle" and "heritage". Whether it 
has been over-commercialized, and whether its spatial suitability is affected, it has become a problem to be verified in protection and development. Martínez (2016) found that the commercial gentrification of the Guozijian historic area in the transformation of Beijing's urban heritage losing the cultural atmosphere. Retnasih S. (2015) found that public appreciation of the heritage building reused as factory outlets and the preservation of the architectural features can affect the intention to visit the stores. Chen (2015a) proposed to improve the atmosphere after the commercialization of historical blocks design principles and countermeasures make it better to be close to the user's psychology, in order to improve the quality of cultural tourism. Chen (2015b) found that a comprehensive value assessment system combining historical and cultural district value assessment systems with sustainable development.

Therefore, this study aims to fulfill the research gaps that mention above. The present study, based on the appeal of stakeholders, analyzes the commercial suitability of historical and cultural blocks are based on the most characteristic Beijing. It retains a large courtyard with the most typical plane, and has the most typical courtyard and neighborhood growth mode and complete "fish bone" texture in Beijing's old city. The majority of traditional buildings with harmonious appearances (Yao \& Dai, 2011).

Hypothesis 1: Overall environmental atmosphere of historical and cultural blocks have a significant influence on public perceptions of commercial suitability.

Hypothesis 2: Commercial atmosphere of historical and cultural blocks have a significant influence on public perceptions of commercial suitability.

Hypothesis 3: Living atmosphere of historical and cultural blocks have a significant influence on public perceptions of commercial suitability.

\section{Research Methodology}

\subsection{Research Design}

The objectives of this current research are to study decision variables of internal and external factors and elements that influence on historical and cultural blocks and to devise the criteria for the commercial suitability evaluation of historical and cultural blocks (Adiwibowoa \& Santosa, 2015).

This research is a quantitative design using survey questionnaire to collect data from people who currently have been to the historical and cultural blocks in Beijing. The research employs ANOVA and Multiple regression to test the relationships and to test hypothesis.

The author used a constructed survey questionnaire to collect the data from the samples. The questionnaire has 3 parts including the basic information of subjects, the basic views of the subjects on the commercial reality of the historical and cultural blocks, the investigation of the Likert scale form.

Part 1: Personal profiles statistics on the basic information of the respondents a total of 4 questions.

Part 2: Questions related to study the basic views of the participants on the 
status of commercialization of historical and cultural blocks a total of 8 questions.

Part 3: Questions related to factors and elements influence on In-depth investigation of commercialization suitability a total of 20 questions.

Of these, Part 3 is scaled questions following the 5 scale of Likert's scale concept. Each question has five different levels of options: "very good", "better", "general", "poor", and "very poor".

\subsection{Population, Sample and Sampling}

Population in these current research composts of people who currently have been to the historical and cultural blocks in Beijing. There are many group of people related to visit the historical and cultural blocks in Beijing including tourists, residents, scholars.

The amount of the aforesaid is unknown; therefore, we use W. G. Cochran's sample size calculation.

$$
n_{0}=\frac{Z^{2} * p *(1-p)}{e^{2}} .
$$

$n_{0}$ - the sample size.

$Z$ - the abscissa of the normal curve that cuts off an area a at the tails, confident level $=1.96$.

$e$ - the acceptable sampling error, not more than 5 percent (0.05).

$p$-the estimated proportion of an attribute that is present in the population.

Thus, the sample size is 387 . However, for easy to collect and process the data, the researcher collect data from 400 samples.

The researcher will apply spatial sampling (A non-probability sampling method of non-stationary, transient, spatially adjacent groups.) in order to collect the data from the samples.

\subsection{Data Collection}

This research is a quantitative designed using spatial sampling.

Since the study is about the commercialization suitability evaluation of historical and cultural blocks, when distributing and collecting questionnaires, several questionnaires are issued at different merchants with even distances to visitors one by one. And the number of copies will be recorded for the statistics.

In the awards section, to encourage participation in the survey, ensure the rate of returning the questionnaire.

The constructed survey questionnaires were translated into Chinese for Chinese respondents in order to ensure the reliability and validity of the research instrument.

The researcher analyzed the data and tested the hypotheses. The researcher summarized the findings and made recommendations. 


\section{Results and Discussion}

\subsection{The Relationship between Gender and Commercial Suitability}

The researcher used a t-Test to find the relationship between data variables (gender and commercial suitability) at a significance level 0.05 .

The result from Table 1 illustrates the relationship between gender and commercial suitability. Since Sig. is 0.172 , which is greater than 0.05 , then 0.411 is selected from Sig (2-tailed) as equal variances assumed. P (possibility) is 0.411 , a (significance level) is 0.05 , so $\mathrm{P}$ is greater than $\alpha$, which is not significant and resulting to accept the null hypothesis.

It is indicated that there is not a significant relationship between gender and commercial suitability at the significance level of 0.05 . The gender has no significant influence on commercial suitability.

\subsection{The Relationship between Age and Commercial Suitability}

The researcher used ANOVA to find the relationship between data variables (age and commercial suitability) at a significant level of 0.05 .

It is indicated that there is not a significant relationship between age and commercial suitability at the significance level of 0.05 . The gender has no significant influence on commercial suitability in Table 2.

\subsection{Description Analysis of Variables}

After the reliability and validity of the research variables are proved, this part lies in the description and analysis of the research variables, and the average values of the research variables are calculated respectively.

Table 3 illustrates that the respondents approved rating for specific evaluation projects of commercial blocks. The majority of the total respondents gave commercial atmosphere in commercial blocks $(\bar{X}=2.65)$, followed by overall environmental atmosphere $(\bar{X}=2.61)$, living atmosphere $(\bar{X}=2.32)$, Inferential

Table 1. The relationship between gender and commercial suitability.

\begin{tabular}{|c|c|c|c|c|c|c|c|c|}
\hline \multirow{2}{*}{$\begin{array}{c}\text { Gender and } \\
\text { commercial suitability }\end{array}$} & \multirow{2}{*}{ Sig. } & \multirow{2}{*}{$\mathrm{t}$} & \multirow{2}{*}{ diff } & \multirow{2}{*}{$\begin{array}{c}\text { Sig. } \\
\text { (2-tailed) }\end{array}$} & \multirow{2}{*}{$\begin{array}{c}\bar{X} \\
\operatorname{diff}\end{array}$} & \multirow{2}{*}{$\begin{array}{l}\text { Std. } \\
\text { Error diff }\end{array}$} & \multicolumn{2}{|c|}{ 95\% Confidence } \\
\hline & & & & & & & Upper & Lower \\
\hline $\begin{array}{c}\text { Equal variances } \\
\text { assumed }\end{array}$ & & -0.84 & 398 & 0.411 & -0.07 & 0.07 & -0.23 & 0.08 \\
\hline $\begin{array}{c}\text { Equal variances not } \\
\text { assumed }\end{array}$ & 0.172 & -0.78 & 189 & 0.450 & -0.07 & 0.09 & -0.22 & 0.12 \\
\hline
\end{tabular}

Table 2. The relationship between age and commercial suitability in Anova.

\begin{tabular}{cccccc}
\hline Model & Sum of squares & df & Mean square & F & Sig. \\
\hline Between Groups & 6.130 & 6 & 1.020 & 2.511 & 0.076 \\
Within Groups & 199.875 & 394 & 0.557 & & \\
total & 205.999 & 400 & & & \\
\hline
\end{tabular}


statistics including t-Test were employed to find the relationships between data variables (gender and consumer's purchasing decisions) and ANOVA was used to compare between data variables (age, education background, salary and consumers' purchasing decisions) for the question number. Linear regression was employed to test hypotheses regarding the relationship between consumers' behavior and purchasing decisions, and marketing mix factors and purchasing decisions.

\subsection{Correlation of Variables}

The above part is to analyze the calculated mean value of the research variable and understand the basic attitude of the sample towards the research variable. This part studies the relationship between variables. Correlation is to study the correlation between two variables. Correlation research often is the first step in a regression analysis. The reason is that there is such a logical relationship: a relationship there does not necessarily have a regression relation, but there is no correlation can't return relationship (if there is no effect, the relationship has to return to the still think there is no relationship between the regression, because must first related to regression relationship). A correlation is a correlation between two variables, but there are usually many research variables. In this study, the correlation coefficients of the four variables were arranged in a table. The format of correlation analysis results of this case is shown in the following table:

The result from Table 4 shows that there was a significant correlation between the variables.

\subsection{Regression Analysis of Variables}

Regression analysis is a statistical analysis method for determining quantitative

Table 3. Descriptive analysis of variables table.

\begin{tabular}{ccccc}
\hline Variable name & $\begin{array}{c}\text { Minimum } \\
\text { value }\end{array}$ & $\begin{array}{c}\text { Maximum } \\
\text { value }\end{array}$ & $\bar{X}$ & SD \\
\hline Overall environmental atmosphere & 1 & 5 & 2.61 & 0.83 \\
Commercial atmosphere & 1 & 5 & 2.65 & 0.88 \\
Living atmosphere & 1 & 5 & 2.32 & 0.83 \\
Commercial suitability & 1 & 5 & 1.99 & 1.07 \\
\hline
\end{tabular}

Table 4. Correlation analysis of variables table.

\begin{tabular}{|c|c|c|c|c|}
\hline Variable name & $\begin{array}{c}\text { Commercial } \\
\text { suitability }\end{array}$ & $\begin{array}{l}\text { Overall } \\
\text { environmental } \\
\text { atmosphere }\end{array}$ & $\begin{array}{l}\text { Commercial } \\
\text { atmosphere }\end{array}$ & $\begin{array}{c}\text { Living } \\
\text { atmosphere }\end{array}$ \\
\hline Commercial suitability & 1 & & & \\
\hline Overall environmental atmosphere & $0.429^{* *}$ & 1 & & \\
\hline Commercial atmosphere & $0.558^{\star *}$ & $0.729^{* *}$ & 1 & \\
\hline Living atmosphere & $0.509^{\star *}$ & $0.623^{* *}$ & $0.738^{\star *}$ & 1 \\
\hline
\end{tabular}

${ }^{* *}$ There was a significant correlation at the 0.01 level (bilateral). 
relationships in which two or more variables are dependent on each other. It is widely used. Regression analysis can be divided into regression analysis and multiple regression analysis according to the number of independent variables involved. According to the number of independent variables, it can be divided into unitary regression analysis and multiple regression analysis. According to the relationship between independent variables and dependent variables, it can be divided into linear regression analysis and nonlinear regression analysis. If only one independent variable and one dependent variable are included in the regression analysis, and the relationship between them can be approximated by a straight line, such regression analysis is called unitary linear regression analysis. If the regression analysis includes two or more independent variables, and there is a linear relationship between the dependent variables and independent variables, it is called multiple linear regression analysis. This research is about commercial atmosphere in commercial blocks, overall environmental atmosphere and living atmosphere have influence relation with commercial suitability. The Tables 5-7 below for details.

The first is through the $\mathrm{F}$ test (that is, the $\mathrm{p}$ value corresponding to the $\mathrm{F}$ value

Table 5. The model summary table ${ }^{\mathrm{b}}$.

\begin{tabular}{cccccc}
\hline Model & $\mathrm{R}$ & $\mathrm{R}^{2}$ & Adjust $\mathrm{R}^{2}$ & Standard error & $\mathrm{DW}$ \\
\hline 1 & $0.815^{\mathrm{a}}$ & 0.664 & 0.657 & 0.507 & 0.2178 \\
\hline
\end{tabular}

${ }^{a}$ Predictive variable, constant, commercial atmosphere, overall environmental atmosphere, living atmosphere. ${ }^{b}$ Dependent variable: commercial suitability.

Table 6. Anova ${ }^{a}$.

\begin{tabular}{cccccc}
\hline Model & Sum of squares & df & Mean square & F & Sig. \\
\hline Regression & 102.102 & 6 & 34.002 & 130.567 & $0.000^{\mathrm{b}}$ \\
residuals & 51.526 & 394 & 0.257 & & \\
total & 152.544 & 400 & & &
\end{tabular}

${ }^{a}$ Dependent variable: commercial suitability. ${ }^{b}$ Predictive variable: constant, commercial atmosphere, overall environmental atmosphere, living atmosphere.

Table 7. Coefficient ${ }^{\mathrm{a}}$.

\begin{tabular}{|c|c|c|c|c|c|c|c|}
\hline \multirow{2}{*}{ Model } & \multicolumn{2}{|c|}{$\begin{array}{c}\text { Non-standardized } \\
\text { coefficient }\end{array}$} & \multirow{2}{*}{$\frac{\begin{array}{c}\text { Standardized } \\
\text { coefficient }\end{array}}{\text { Beta }}$} & \multirow{2}{*}{$t$} & \multirow{2}{*}{ Sig. } & \multicolumn{2}{|c|}{ Col-linear statistics } \\
\hline & B & Standard error & & & & Tolerance & VIF \\
\hline Constant & 0.178 & 0.188 & & 0.954 & 0.341 & & \\
\hline Living atmosphere & 0.453 & 0.057 & 0.428 & 7.848 & 0.02 & 0.570 & 1.754 \\
\hline $\begin{array}{c}\text { Overall environmental } \\
\text { atmosphere }\end{array}$ & 0.478 & 0.061 & 0.455 & 7.810 & 0.01 & 0.498 & 2.003 \\
\hline $\begin{array}{l}\text { Commercial } \\
\text { atmosphere }\end{array}$ & 0.032 & 0.057 & 0.29 & 0.535 & 0.492 & 0.573 & 1.743 \\
\hline
\end{tabular}

${ }^{a}$ Dependent variable: commercial suitability. 
is less than 0.05 , indicating that there will be at least one independent variable DV in the study, which will affect the dependent variable IV. Second, the fitting effect of the model is explained. Analyze $\mathrm{R}^{2}$, DW, VIF. $\mathrm{R}^{2}$ represents all the independent variables that we're studying and IV will account for the change in the dependent variable DV. DW is near 2, indicating no auto-correlation. A VIF value less than 5 indicates that there is no multicollinearity. The third is to study the influence of independent variable IV on the dependent variable DV. P value, less than 0.05 , indicates that the independent variable IV will have an influence on the dependent variable DV, and B or Beta values are both positive, indicating a positive influence. Finally, the magnitude of the influence of each independent variable IV on the dependent variable DV is compared, and the value of B is determined directly according to the significant independent variable IV.

\section{Conclusion and Implication}

\subsection{Research Summary}

The stakeholders of historic buildings conservation are diversified, including at least the government, enterprises, the people (residents and tourists). All of these stakeholders have their own interest demands. Conflicts of interest are inevitable.

Meet multiple stakeholders. Reasonable commercial development can inject fresh blood into the protection and development of historical and cultural blocks, and make them revitalize again. Moderate commercialization is the optimal development mode for the protection and development of historical and cultural blocks. However, excessive commercialization and insufficient commercialization often exist in the commercialization practice of historical and cultural blocks, which can easily lead to the destruction of block culture and the loss of vitality of sustainable development. Therefore, it is necessary to carry out effective control and management policies to guide the appropriate commercial development of the block. Based on this, the paper studies the factors related to the suitability of commercial development in historical and cultural blocks. Taking the typical historical and cultural blocks in the main urban area of Beijing as a case, this paper conducts an empirical study on their commercial suitability degree, and designs a questionnaire survey from the perspective of the overall environment, commercial atmosphere, and living atmosphere as independent variables, in order to seek a reasonable commercial suitability degree.

Finally, it puts forward the optimal policy of commercialization suitability of historical and cultural blocks. Combined with various demands of stakeholders, from the policy management, planning technology and social aspects to put forward a comprehensive appropriate commercialization strategy. According to the specific development situation of different historical and cultural blocks, commercial transformation or optimization and upgrading should be carried out to realize the sustainable and coordinated development between the development and utilization of historical blocks and cultural protection. Policy management: commercial management system on the premise of protection; Tech- 
nical level of planning: continue the commercial model of the main function of the block; at the social level of the block, the block optimization coordinated with the social structure should improve the community construction, encourage employment and commercial activities, enhance cultural confidence and carry forward the national spirit.

\subsection{Research Limitation}

The commercialization degree of historical and cultural districts is affected by many factors such as geographical location, traffic conditions, historical background and development level, etc. However, this paper only takes typical districts in Beijing as an example, without investigation and in-depth study of other places, which leads to certain limitations in the application scope of the conclusion. At present, there is a lack of historical and cultural blocks suitable for commercialization in Beijing, which leads to the incomplete scope of empirical research objects and the lack of persuasion in the research conclusions.

The research on commercialization suitability evaluation of historical and cultural blocks involves a wide range of contents, but the research methods and analysis tools adopted in this paper are one-sided, in some extent, and more exploration should be done in the selection of research methods. As the data source of the evaluation in this paper is mainly based on questionnaire survey, people from different regions have different attitudes towards things. However, due to the limitation of time and manpower, and even the influence of the epidemic, the sample size of the questionnaire is not enough, which affects the accuracy of the research data to a certain extent.

In the future research, on the one hand, a variety of technical means will be used to collect and optimize the dynamic information of historical block protection and commercial development from multiple dimensions. In addition, qualitative and quantitative methods are combined to support the scientific and rational evaluation results; thirdly, expand the scope of empirical research, and enrich and deepen the evaluation by investigating and summarizing data from a wider range of regions, so as to obtain feasible policy research.

\section{Conflicts of Interest}

The authors declare no conflicts of interest regarding the publication of this paper.

\section{References}

Adiwibowoa, R. S., Widodo, P., \& Santosa, I. (2015). Correlations between Public Appreciation of Historical Building and Intention to Visit Heritage Building Reused as Retail Store. Social and Behavioral Sciences, 184, 357-364.

Chen, L. L. (2015a). Study on the Atmosphere of Pedestrian Space in Commercial Historical District Based on Post-Use Evaluation-A Case Study of Chengdu City. Master Thesis, Chengdu: Southwest Jiaotong University.

Chen, A. (2015b) Study on the Value Evaluation of Historical and Cultural Block Based 
on the Perspective of Sustainable Development. Master Thesis, Chongqing: Chongqing University.

De Santoli, L. (2009). Historic Buildings: Conservation, Management and Policy Issues. In Sustainable Built Environment Vol. II Historic Buildings: Conservation, Management and Policy Issues.

Ge, J. L. (2007). Research on Tourism Business Perception and Regulation Mechanism of Zhouzhuang Ancient Town. Master Thesis, Nanjing: Nanjing Normal University.

Liao, T. (2017). On the Appeal of Stakeholders and Influence for Historical and Cultural block-Taking Chengdu as an Example. Ph. D. Thesis, Chengdu: Southwest Jiaotong University.

Lan, Z. J. (2015). Excessive Commercial "Killing” Ancient Construction. http://www.taiwan.cn/plzhx/dlgc/201501/t20150114_8695645.htm

Martínez, P. G. (2016) Authenticity as a challenge in the transformation of Beijing's urban heritage: The commercial gentrification of the Guozijian historic area. Cities, 59, 48-56.

Ruan, Y. S. (2015). Retaining Homesickness - The Return of Cultural Hometown under the New Normal. Urban and Rural Development, 492, 9.

Wu, Z. Z. (2012). Based on Game Theory Research the Protection Strategy of Han Chang'an City Ruins. Urban Problem, 208, 37-41.

Xing, L. Y. (2019).Evaluation of Commercialization Degree and Spatial Suitability of Pingjiang Historical and Cultural Districts from "Perception" to "Quantification". Intelligent City, 17, 5-8

Yao, D., \& Dai, D. S. (2011). From "Space Reconstruction" to "Value Reconstruction"-Research on the Conservation Strategy of Historic Blocks. Architectural Journal, 5, 36-39. 